\title{
Modified Method for Obtaining the Critical Cooling Rate for Vitrification of Polymers
}

\author{
Claudia Canova, Benjamim de Melo Carvalho* \\ Materials Engineering Department, Universidade Estadual de Ponta Grossa - UEPG, \\ 84030-900 Ponta Grossa - PR, Brazil
}

Received: May 31, 2007; Revised: October 30, 2007

\begin{abstract}
Due to the relevance of the critical cooling rate, Rc, for glasses, Barandiarán and Colmenero (BC) developed a method for calculating Rc as a function of the crystallization temperature on cooling obtained from thermal analysis. The critical cooling rate is obtained by the extrapolation method to conditions of infinity undercooling. However, for polymers, there is a strong reason for modifying the original BC method. In this case, the extrapolation must be extended only to the undercooling associated to the glass transition temperature, $\mathrm{Tg}$, because no crystallization can occur below this temperature. Following this modified method (MBC) proposed by the present authors, the critical cooling rate for PP, PEEK, P10MS and PET were determined. The results showed that the new values are much lower than those obtained by the original $\mathrm{BC}$ method.
\end{abstract}

Keywords: critical cooling rate, noncrystalline polymers, crystallization, P10MS, PP

\section{Introduction}

In crystalline materials, the control of properties can be achieved by controlling the crystallization process. In some cases, it is desirable to avoid any crystallization. For example, if transparency is important or if one wants to measure the glass transition temperature with greater precision using Differential Scanning Calorimeter (DSC), amorphous polymers can be more appropriated. In the injection molding, depending on how fast some polymers are cooled, an amorphous or crystalline part can be obtained. Therefore, in these cases it is important to know what is the lowest (critical) cooling rate that avoids the crystalline phase formation.

Due to the importance of the crystallization process for glasses, Barandiarán and Colmenero (BC) developed a method for obtaining the critical cooling rate using non isothermal crystallization temperature as a function of cooling rate from thermal analysis ${ }^{1}$. Fitting these experimental data to their model, represented by the Equation 1, the critical rate Rc is obtained by an extrapolation method to conditions of infinity undercooling:

$$
\begin{aligned}
& \ln (\mathrm{R})=\mathrm{A}-\left(\mathrm{B} /\left(\mathrm{T}_{\mathrm{m}}{ }^{\circ}-\mathrm{T}_{\mathrm{c}}\right)^{2}\right) \\
& \mathrm{Rc}^{(\infty)}=\exp (\mathrm{A})
\end{aligned}
$$

where $\Delta \mathrm{T}$ is the degree of undercooling $\left(\Delta \mathrm{T}=\mathrm{T}_{\mathrm{m}}{ }^{\mathrm{o}}-\mathrm{T}_{\mathrm{c}}\right), \mathrm{T}_{\mathrm{m}}{ }^{\circ}$ the equilibrium melting temperature, $\mathrm{T}_{\mathrm{c}}$ is the crystallization temperature observed in a DSC experiment at a cooling rate $\mathrm{R}$, and $\mathrm{Rc}^{(\infty)}$ is the critical cooling rate.

However, in some cases the critical cooling rates obtained by this method are very high and probably overestimated ${ }^{2,3}$. Cabral Jr. et al. ${ }^{4}$ observed correctly that the extrapolation to infinity undercooling does not make sense. The reason is that this extrapolation can be achieved only mathematically but not physically, since negative crystallization temperatures should be necessary. So, the maximum undercooling actually possible is obtained if Tc is equal zero Kelvin. Thus, the recent modification proposed by Cabral Jr. et al. ${ }^{4}$ employs the extrapolation to this maximum possible undercooling:

$$
\begin{aligned}
& \ln \left(\mathrm{Rc}^{(0 \mathrm{~K})}\right)=\mathrm{A}-\left(\mathrm{B} /\left(\mathrm{T}_{\mathrm{m}}{ }^{\circ}-0 \mathrm{~K}\right)^{2}\right) \\
& \mathrm{Rc}^{(0 \mathrm{~K})}=\exp \left(\mathrm{A}-\mathrm{B} /\left(\mathrm{T}_{\mathrm{m}}{ }^{\circ}\right)^{2}\right)
\end{aligned}
$$

However, at least for polymers, there is a strong reason for introducing a more conceptual modification to the original BC method. In this paper, the authors propose a modification on the $\mathrm{BC}$ method, where the extrapolation is extended only to the undercooling associated to the glass transition temperature $\mathrm{T}_{\mathrm{g}}$, since no crystallization can occur below this temperature. Therefore, the aim of this paper is to compare, for different polymers, the Rc values obtained by the original $\mathrm{BC}$ method $^{1}$ and the modified method proposed by Cabral Jr. et al. ${ }^{4}$ with the results obtained by the MBC method proposed by the present authors.

\section{Materials and Methods}

Using the modified method proposed in the present work, the new critical cooling rate is obtained by Equation 5:

$$
\begin{aligned}
& \ln \left(\mathrm{Rc}^{(\mathrm{Tg})}\right)=\mathrm{A}-\left(\mathrm{B} /\left(\mathrm{T}_{\mathrm{m}}{ }^{\mathrm{o}}-\mathrm{T}_{\mathrm{g}}\right)^{2}\right) \\
& \mathrm{Rc}^{(\mathrm{Tg})}=\exp \left(\mathrm{A}-\left(\mathrm{B} /\left(\mathrm{T}_{\mathrm{m}}{ }^{\circ}-\mathrm{T}_{\mathrm{g}}\right)^{2}\right)\right.
\end{aligned}
$$

In this paper, experimental data of crystallization temperature and cooling rates obtained by DSC for some polymers - homopolymer polypropylene ${ }^{5}$ (PP), Poly-ether-ether-ketone ${ }^{6}$ (PEEK), Poly(decamethylene sebacate) ${ }^{3}$ (P10MS) and poly(ethylene terephthalate $)^{7}(\mathrm{PET})$ - were selected from the literature. They were used to evaluate the critical cooling rates according to the original $\mathrm{BC}$ method, expressed by Equation 2, by the modified method proposed by Cabral Jr. et al. ${ }^{4}$, Equation 4 and by the modified BC method, MBC, expressed by Equation 6 . These polymers were chosen because they present different crystallization kinetics. Polypropylene and P10MS present very fast crystallization rate, while PEEK and PET show slow crystallization rate. The equilibrium melting temperature and 
the glass transition temperature for PP, PEEK, P10MS and PET are presented in Table $1^{3,5,7}$. Tables 2 and 3 present the crystallization temperature as a function of cooling rate for $\mathrm{PEEK}^{6}$, polypropylene ${ }^{5}$,

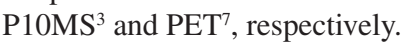

\section{Results and Discussion}

On Figure 1, the experimental crystallization data as a function of the undercooling degree for PEEK were fitted by Equation 1. The difference between the extrapolation necessary for obtaining the $\mathrm{Rc}$ for $\mathrm{BC}$ and $\mathrm{MBC}$ methods can be seen. The intersection of the regression line with the undercooling associated to $\mathrm{Tg}$ (dotted vertical line) corresponds to $\operatorname{lnR} c^{(\mathrm{Tg})}$ for the MBC method, while $\operatorname{lnRc^{(\infty )}}$ corresponds to the intersection between the regression line with the $\mathrm{y}$-axis in the original $\mathrm{BC}$ method. It is clear that the value of $\operatorname{lnRc^{(Tg)}}$ calculated by the MBC method is lower than that one obtained by the $\mathrm{BC}$ method.

Figure 2 shows the experimental crystallization data and the undercooling degree of PP fitted by Equation 1. It also can be demonstrated that $\mathrm{Rc}^{(\mathrm{Tg})}$ value evaluated by MBC method is lower than that one obtained by the original BC method. As it was described for Figures 1 and 2, the experimental crystallization data for P10MS and PET are presented on Figures 3 and 4.

Table 1. Glass transition temperature and equilibrium melting temperature for the samples used in the present work ${ }^{3,5,7}$.

\begin{tabular}{crccr}
\hline Sample & \multicolumn{1}{c}{ PP } & PEEK & P10MS & PET \\
\hline $\mathrm{Tg}\left({ }^{\circ} \mathrm{C}\right)$ & 6.5 & 148.5 & -53 & 67.2 \\
$\mathrm{~T}_{\mathrm{m}}{ }^{\circ}\left({ }^{\circ} \mathrm{C}\right)$ & 187.2 & 357.3 & 92.4 & 280.2 \\
\hline
\end{tabular}

Table 2. Crystallization temperature Tc as a function of cooling rate $\mathrm{R}$ for $\mathrm{PP}^{5}$ and $\mathrm{PEEK}^{6}$.

\begin{tabular}{ccc}
\hline Cooling rate $\mathrm{R}\left({ }^{\circ} \mathrm{C} / \mathrm{min}\right)$ & $\mathrm{Tc}\left({ }^{\circ} \mathrm{C}\right)$ for PP & $\mathrm{Tc}\left({ }^{\circ} \mathrm{C}\right)$ for PEEK \\
\hline 5 & 114.6 & 307.5 \\
10 & 110.4 & 301.1 \\
20 & 108.2 & 293.2 \\
30 & 101.9 & - \\
40 & 102.9 & - \\
50 & 98.5 & - \\
\hline
\end{tabular}

Table 3. Crystallization temperature as a function of cooling rate for $\mathrm{P} 10 \mathrm{MS}^{3}$ and $\mathrm{PET}^{7}$.

\begin{tabular}{cccc}
\hline $\mathrm{R}$ & $\mathrm{Tc}\left({ }^{\circ} \mathrm{C}\right)$ & $\mathrm{R}$ & $\mathrm{Tc}\left({ }^{\circ} \mathrm{C}\right)$ \\
$\left({ }^{\circ} \mathrm{C} / \mathrm{min}\right)$ & $\mathrm{P} 10 \mathrm{MS}$ & $\left({ }^{\circ} \mathrm{C} / \mathrm{min}\right)$ & $\mathrm{PET}$ \\
\hline 0.2 & 55.3 & 2 & 211.4 \\
2 & 52.4 & 3 & 206.3 \\
10 & 48.7 & 4 & 200.9 \\
20 & 45.9 & 7.5 & 198.9 \\
30 & 42.8 & 10 & 189.1 \\
40 & 42.5 & 20 & 176.8 \\
50 & 39.8 & 30 & 165.6 \\
- & - & 50 & 162.9 \\
\hline
\end{tabular}

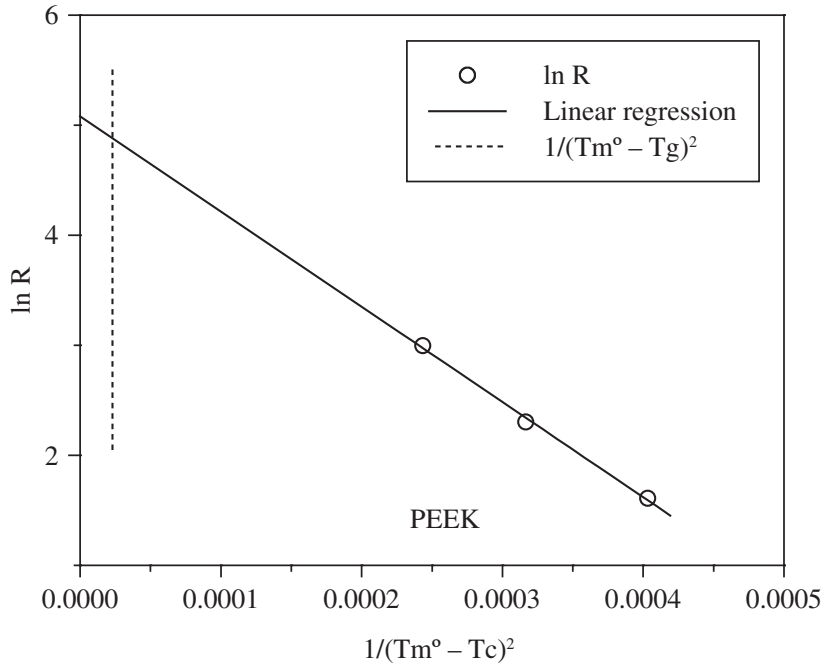

Figure 1. Fitting of the crystallization data to Equation 1 for obtaining the critical cooling rate for vitrification of PEEK. Vertical line represents the undercooling associated to $\mathrm{Tg}$.

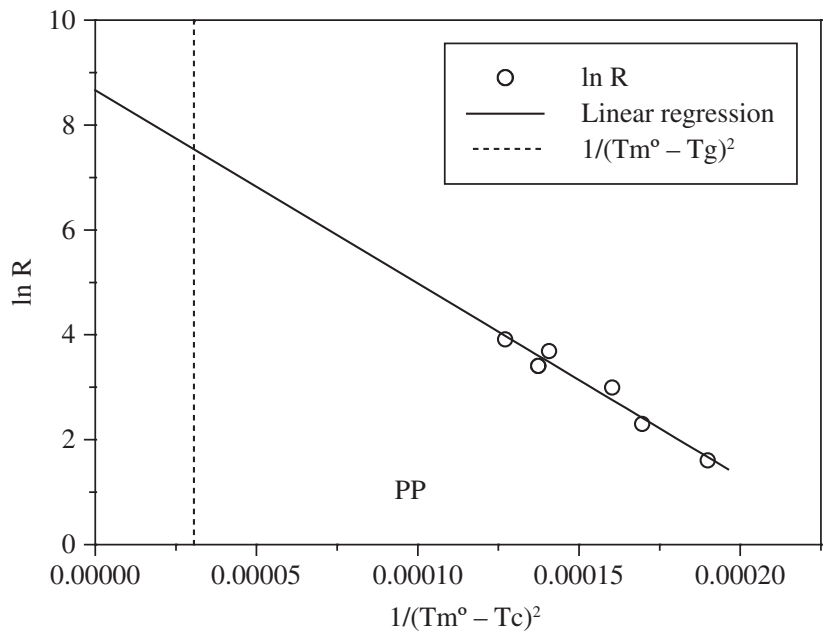

Figure 2. Fitting of the crystallization data to Equation 1 for obtaining the critical cooling rate for vitrification of PP. Dotted vertical line represents the undercooling associated to $\mathrm{Tg}$.

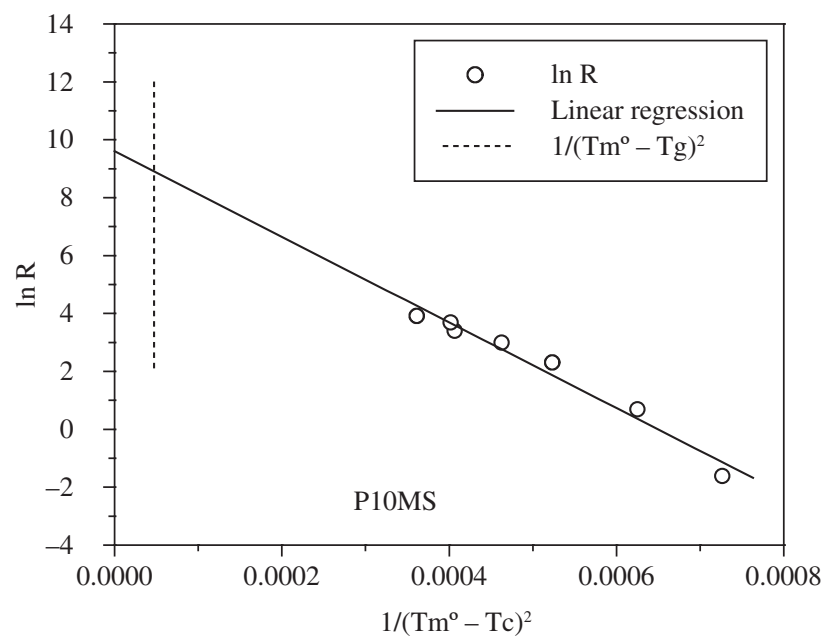

Figure 3. Fitting of the crystallization data to Equation 1 for obtaining the critical cooling rate for vitrification of P10MS. Dotted vertical line represents the undercooling associated to $\mathrm{Tg}$. 
Figure 1-4 show that the experimental crystallization data from literature for the different polymers is relatively fitted by Equation 1, at least for the range of cooling rates employed in the present work.

Table 4 presents the values of the critical cooling rates for PEEK, PP, PET and P10MS according to the BC and MBC methods. It can be seen that for PEEK the $\mathrm{Rc}^{(\mathrm{Tg})}$ obtained by the modified method corresponds to $82 \%$ of that one calculated by the original $\mathrm{BC}$ method. In case of the PP, the difference is much higher, being the $\mathrm{Rc}^{(\mathrm{Tg})}$ calculated by the MBC method correspondent to $32 \%$ of that obtained by the original BC method. The Rc for PEEK is not so high and it is coherent with the relative facility to obtain an amorphous PEEK sample by quenching from the melt state. However, the value of Rc for the homopolymer PP is still very high, even if it is calculated by the MBC method. This value is coherent with the known difficulty (or impossibility in practical conditions) to obtain an amorphous PP sample.

For PET, Table 4 shows that the critical cooling rates are not so high, similarly to the results obtained for PEEK. That is also coherent with the fact that it is relatively easy to obtain an amorphous sample of this polymer. For P10MS, Table 4 shows that the $\mathrm{Rc}^{(\mathrm{Tg})}$ value calculated by the $\mathrm{MBC}$ method proposed in the present work is $50 \%$ lower than that one predicted by the original method. However, it is still extremely high, as mentioned by Guimarães and Zanotto ${ }^{3}$. This fact confirms the experimentally observed difficulty to vitrify this polymer, which is probably due to the high molecular mobility associated to its very flexible polymer chain ${ }^{3}$.

Table 4 also allows one to compare the Rc values obtained by the modified methods proposed by Cabral Jr. et al. ${ }^{4}, \mathrm{Rc}^{(0 \mathrm{~K})}$, and the present authors, $\mathrm{Rc}^{(\mathrm{Tg})}$, which employ the extrapolation to zero Kelvin and Tg, respectively. The ratio between these Rc values and

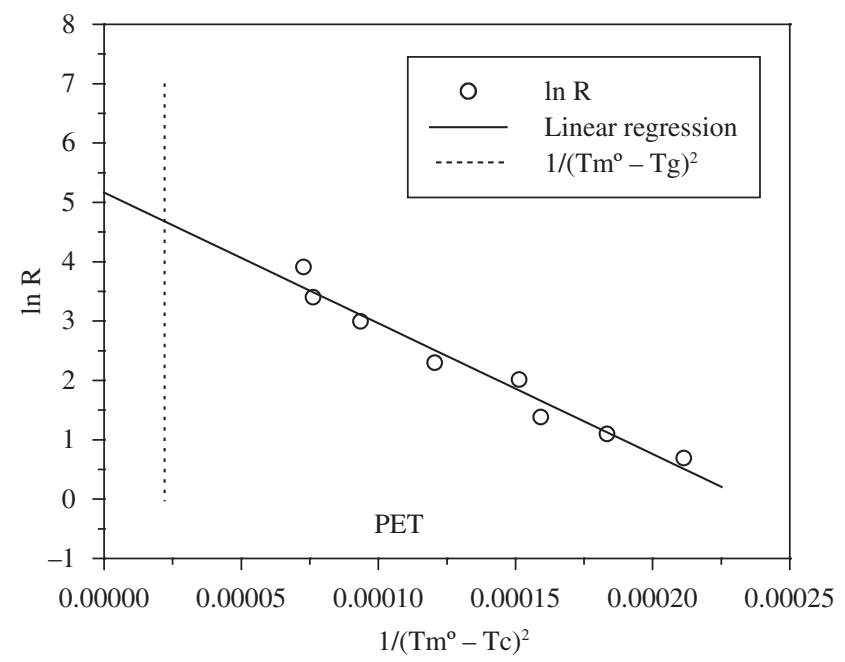

Figure 4. Fitting of the crystallization data to Equation 1 for obtaining the critical cooling rate for vitrification of PET. Dotted vertical line represents the undercooling associated to $\mathrm{Tg}$.
$\mathrm{Rc}^{(\infty)}$ is showed on Table 4. It can be seen that the difference between these modified methods is significant. For PP, the $\mathrm{Rc}^{(0 K)}$ obtained by the extrapolation to zero Kelvin is $84 \%$ of the original value $\mathrm{Rc}^{(\infty)}$. However, $\mathrm{Rc}^{(\mathrm{Tg})}$ is only $32 \%$ of $\mathrm{Rc}^{(\infty)}$. For P10MS, the ratio $\mathrm{Rc}^{(0 \mathrm{~K})} / \mathrm{Rc}^{(\infty)}$ is 0.9 , while $\mathrm{Rc}^{(\mathrm{Tg})} / \mathrm{Rc}^{(\infty)}$ is 0.5 . For PET, $\mathrm{Rc}^{(0 \mathrm{~K})} / \mathrm{Rc}^{(\infty)}$ is 0.93 , while $\mathrm{Rc}^{(\mathrm{Tg})} / \mathrm{Rc}^{(\infty)}$ is 0.62 . For PEEK, $\mathrm{Rc}^{(0 K)}$ is only $3 \%$ lower than the $\mathrm{Rc}^{(\infty)}$ predicted by the original $\mathrm{BC}$ method. However, the difference between $\mathrm{Rc}^{(\mathrm{Tg})}$ and the original value $\mathrm{Rc}^{(\infty)}$ is significant, which is demonstrated by the ratio $\mathrm{Rc}^{(\mathrm{Tg})} / \mathrm{Rc}^{(\infty)}$ equal to 0.82 .

The modified method proposed by the present authors allows a significant reduction of critical cooling rate compared to the original method. However, it is important to point out that any uncertainty in the determination of $\mathrm{T}_{\mathrm{m}}{ }^{\mathrm{o}}$ will have a very large effect on the predicted Rc. For instance, in case of P10MS, Guimarães and Zanotto ${ }^{3}$ observed that according to the chosen value of $\mathrm{T}_{\mathrm{m}}{ }^{\mathrm{o}}$, the parameter $\mathrm{Rc}^{(\infty)}$ can assume values between $3000{ }^{\circ} \mathrm{C} / \mathrm{min}\left(\mathrm{T}_{\mathrm{m}}{ }^{\mathrm{o}}=83{ }^{\circ} \mathrm{C}\right)$ and $15000^{\circ} \mathrm{C} / \mathrm{min}\left(\mathrm{T}_{\mathrm{m}}{ }^{\circ}=92.4^{\circ} \mathrm{C}\right)$. This large difference overcomes the influence of the modified method proposed by the present authors. Therefore, any test of this modified method with experimental data must be associated to a great confidence on the $\mathrm{T}_{\mathrm{m}}{ }^{\mathrm{o}}$ values of the polymer sample. With the recent development of the chip calorimetry ${ }^{8}$, it will be possible to determine with precision the experimental critical cooling rate for vitrification of several polymers.

Finally, it should be mentioned that with high cooling/heating rates, there is a significant temperature lag between the DSC furnace and the sample ${ }^{9-11}$. If one intends to test the theoretical methods for obtaining the critical cooling rate, this effect also must be taken into account.

\section{Conclusion}

At least for polymers, the original BC method is not completely adequated. The modified method proposed in the present work showed that significant lower critical cooling rates can be obtained for polymers when the extrapolation is extended only to the undercooling associated to $\mathrm{T}_{\mathrm{g}}$. Probably, these new critical cooling rates calculated by the $\mathrm{MBC}$ method are more realistic or, at least, are more consistent with theoretical fundaments of polymer crystallization. It is expected that the recent developments of new experimental techniques will be very helpful in the validation of the available theoretical methods.

\section{References}

1. Barandirán JM, Colmenero J. Continuous cooling approximation for the formation of a glass. Journal of Non-Crystalline Solids. 1981; 46(3):277-287.

2. Guimarães LM. Testes das teorias clássicas de nucleação e crescimento de cristais no poli(sebacato de decametileno). [Unpublished D. Phil thesis]. São Carlos: Universidade Federal de São Carlos; 2002.

3. Guimarães LM, Zanotto ED. Cristalização e taxa crítica de resfriamento para vitrificação do poli(sebacato de decametileno). Química Nova. 2003; 26(2):202-207.

4. Cabral AA, Cardoso AAD, Zanotto ED. Glass-forming ability versus stability of silicate glasses. I. Experimental test. Journal of Non-Crystalline Solids. 2003; 320(1):1-8.

Table 4. Critical cooling rates obtained for PP, PEEK, P10MS and PET by the original Barandiarán and Colmenero method, Rc ${ }^{(\infty)}$, and by the Modified Barandiarán and Colmenero methods, $\mathrm{Rc}^{(\mathrm{Tg})}$ and $\mathrm{Rc}^{(0 \mathrm{~K})}$.

\begin{tabular}{lccccc}
\hline & $\operatorname{Rc}^{(\infty)}\left({ }^{\circ} \mathrm{C} / \mathrm{min}\right)$ & $\mathrm{Rc}^{(\mathrm{Tg})}\left({ }^{\circ} \mathrm{C} / \mathrm{min}\right)$ & ${\mathrm{Ratio} \mathrm{Rc}^{(\mathrm{Tg})} / \mathrm{Rc}^{(\infty)}}$ & $\mathrm{Rc}^{(0 \mathrm{~K})}\left({ }^{\circ} \mathrm{C} / \mathrm{min}\right)$ & $\mathrm{Ratio}^{(0 \mathrm{~K})} / \mathrm{Rc}^{(\infty)}$ \\
\hline PP & 5789 & 1874 & 0.32 & 4865 & 0.84 \\
PEEK & 161 & 132 & 0.82 & 157 & 0.97 \\
P10MS & 14828 & 7369 & 0.50 & 13274 & 0.90 \\
PET & 175 & 108 & 0.62 & 163 & 0.93 \\
\hline
\end{tabular}


5. Isayev AI, Catignani BF. Crystallization and microstructure in quenched slabs of various molecular weight polypropylenes. Polymer Engineering and Science. 1997; 37(9):1526-1539.

6. Carvalho BM, Bretas RES. Crystallization Kinetics of a PEEK/LCP Blend. Journal of Applied Polymer Science. 1995; 55(2):233-246.

7. Sajkiewicz P, Carpaneto L, Wasiak A. Application of the Ozawa model to non-isothermal crystallization of poly(ethylene terephthalate). Polymer. 2001; 42(12):5365-5370.

8. Adamovsky SA, Minakov AA, Schick C. Scanning microcalorimetry at high cooling rate. Thermochimica Acta. 2003; 403(1):55-63.
9. Janeschitz-Kriegl H, Wippel H, Paulik C, Eder G. Polymer crystallization dynamics, as reflected by differential scanning calorimetry. Part 1: On the calibration of the apparatus. Colloid and Polymer Science. 1993; 271(12):1107-1115.

10. Wu CH, Eder G, Janeschitz-Kriegl H. Polymer crystallization dynamics, as reflected by differential scanning calorimetry. Part 2: Numerical simulations. Colloid and Polymer Science. 1993; 271(12):1116-1128.

11. Carvalho BM, Bretas RES. Determinação da constante cinética de cristalização não isotérmica de polipropilenos modificados com ácido acrílico e anidrido maleico. Polímeros. 2006; 16(4):305-311. 